\title{
The Research of Dress Skills in Online Games
}

\author{
Yuemei Gao ${ }^{1, \text { a }}$
}

${ }^{1}$ Jiangxi Science \& Technology Normal University, Art College, Nanchang, Jiangxi, 330013

a email

Keywords: Online games; Clothing Dress; Tips

\begin{abstract}
In recent years, due to China's economic stimulus, development of the industry has made great progress, especially in the online game industry. In the increasingly fast pace of modern life, people are more and more pressure, have to go through all kinds of entertainment to vent pressure of the heart. People online are the main means of entertainment to relax, there are stimulating adventure, beautiful people and gorgeous costumes, everything to bring people new experience. Where people dress collocation is to bring more people to enjoy the visual, reflecting the modern aesthetic point of view. In this paper, a simple analysis of the network game apparel design role, and about the network game character costumes with skills.
\end{abstract}

\section{Introduction}

People for the first impression of a game is good or bad, depending on the game screen and the characters view, beautiful picture of the game and charismatic character of the game is to stimulate people's desire for basic standards. If bad first impression, then there will be a next game who care about the story yet. Therefore, when making a game, you need to pay attention to character design. The game characters designed to meet the needs of mainstream modern people's aesthetic, which not only take into account people's own image design, while also taking into account the character dress with such game characters will be set in line with people's tastes, in order to give it impressed.

\section{Clothes Reflect Role in People Design}

Character design is the role of design in one, the other is animal design. At present, China's animation and game industry in order to design the most frequent characters, is the most widely used application. Key to making games is reflected in the character design, set a good persona is most likely attracted the people's attention. Therefore, the character's image is extremely important, not only we need to figure itself excellent image, but also designed to meet the character background, age, personality and environmental factors such as location of the clothing, both with the characters to personality characteristics and cultural background reflected most vividly. This designer, no doubt, is a huge challenge, requiring designers with unique design philosophy, but also the role of the game to fully grasp.

\section{Features Reflect in Apparel Design}

Introduction to functional clothing apparel based on that, it is an essential part of the nature of the clothing belonging to an indispensable part. Life, we all know the role of clothing, which is to maintain the image of the basic conditions. People in psychology, also mentioned clothing features to understand a person's personality traits, often, language, action and clothing found in focus from the facial expression. Visible, clothing of the characters reflect importance.

In the function embodied in clothing, clothing occupies only part of the function of gender, as well as additional features decorative and symbolic function. Modern large-scale online games, all have revise apparel and clothing decorative function through modified so that people can be more in line with the image of character. The symbolic function identification, etiquette, card body, belief, all play an important role.

In real life, the clothing features may be embodied in materiality, it has practical, such as the 
ability to keep warm, safe, comfortable and easy activity, or have to resist the harmful effects and so on. However, in game design, as long as the designers imagination to design clothes on the line, you do not need to take into account the actual production and use, of course, clothing to be able to meet the game's background.

\section{The Importance of Online Games Dress Design}

As we all know, the game is out of the plastic arts often realistic themes, close unrestrained imagination and created, which have the characteristics of fantasy. But art is not capable of modeling a simple form, it will definitely have a real image of the many complicated details, rich in detail and how these reflected, which requires the designer's imagination and endurance test, and the time of creation but also with the concept of modern clothing and fashion elements, so that the image is more reasonable. At the same time making the game, whether it is human, and animal designs are based on the main characteristics of the human mind, they are bound to the characteristics of real presence.

In the early game experience, many of the game screen scenes and characters mix felt obvious lack of coordination, which is mainly reflected in the role of painting style and the picture has a background difference, obviously looking very rough character, which contradictions caused by the lack of performance skills. A domestic popular online game, World of Warcraft armor on the character design, but also with the character will not only improve the level of change and vary according to functions. At the same time, the game based on the epic myth of European background, with European classical cultural characteristics, so the design of clothing is going to be the role of the European reference armor cold weapons to enable them to comply with the background of the period, which is able to attract attention s reason.

\section{Clothing Skills in Network Game}

Uniform clothing style is the style, accessories, colors and materials unite to have a singular charm to attract people's attention, but also can fully reflect the character of the people, causing human sympathy. Clothing style is mainly reflected in the image of the character style, accessories with clothing style concept is secondary to character image more vividly reflected. Therefore, on how to coordinate the relationship between clothing and accessories it is particularly important. If the two can style with a perfect, it can better reflect the character style. On the contrary, it will have a negative impact on the character style.

Accessories have their own unique style, or agile and lively, or elegant and quiet, or wanton publicity, etc., with different accessories has a very important influence on different clothing. Thus, during the match between clothing and accessories when they need to focus on the style embodied in reasonable match. For example, game characters designed for women, wearing an elegant dress reflects, they can do in their hair on one side of white flowers, so it better reflects the character of the romantic style. Accessories are not necessarily choose to spend, it can be a necklace, earrings, shoes, bracelets and so on. For character style, with clothing also close to the character style to match, such as the simple style, then dress with relatively simple styling will ably.

Color is an important element in fashion design considerations. In real life, often inseparable from the discussion of clothing color, clothing stores and fashion magazines are also divided according to the color of the clothes are classified. Even pop in a different color to resolve a person's character. It reflects more subtle change is people, people in transition between silent ideology, For designers, the color of their expression characteristics of the times, the focus of social emotional way.

Color selection of clothing in the game, the designer thought would use color to obscure expression. Such as an expression of ideological passion can use strong colors to express the idea of quiet gentle pastel colors can be used. With different degrees of color to know character designer on the role of knowledge and ideas clearly reflect the characters.

With fashion design conditions 4.3 Materials 
On the game character design, clothing material is also a manifestation of Characters basis. To do this successfully is not a simple matter, it will be the first test of the designer of the clothing material understanding and the ability to feel. Women as well as to reflect the kind of soft facial features, you can use lightweight materials, soft, flowing silk or chiffon class. If then with ornaments to dress or shirt style better reflect women's soft. And it reflects male power and strong fabric can be used, its hardness can male characteristics fully reflected. Therefore, designers in apparel design, we need to carefully follow these rules, even fanciful imagination, but also need to keep in mind. Based on these rules as a precondition to understand the nature of the characters, in order to create outstanding works, avoid any unreasonable problems.

\section{Conclusion}

As a game designer needs to understand the distinction between reality and virtual, but also know how to combine the real and virtual characteristics, play to their imagination to create a real fashion elements both have elements of fantasy costumes. Mobilize itself in the creation of all clothing ideas, and create gorgeous beautiful garments add luster to the world of online games, online games for people who love to enjoy the visual pleasure, and feel creative thinking brings a new experience. Modern life, everyone has their own idea of fashion, we will certainly provide more ideas for the game of fashion design various clothing after conception are constantly brewing, and burst out.

\section{Acknowledgements}

Jiangxi Science \& Technology Normal University Dr. Research Fund Project "Film Industry in China since the Reform and Opening and Countermeasures."

\section{References}

[1] Li Xishou. Arts RPG game character set features and methods of analysis [J]. Art \& Design (theory), 2014,12: 88-90.

[2] Zhuang Xiaowen. Accessories Design cartoon characters contemporary film study [J]. 2014, 09: 192-195.

[3] Sheng Nan. costume design in game character design use [J]. world news, 2011, 04: 202-203.

[4] Sun Xiaoxiao, Ye Chenhan. Game armor design analysis techniques-role-playing game "Warhammer Online" as an example [J]. Hefei University (Social Science Edition), 2013, 04: 103-107.

[5] Zhang Lihua, Wang Chuan. Discussion game clothing [J]. Tianjin Textile Science, 2009, 04: 46-49. 